\title{
Composite social health index: Development and assessment in provinces of Iran
}

\author{
Fariba Zamankhani ${ }^{1}$, Kambiz Abachizadeh*2,3 ${ }^{2}$ Soheila Omidnia ${ }^{4}$, Alireza Abadi ${ }^{5,3}$, \\ Mohammad Ali Hiedarnia ${ }^{3}$
}

\section{Abstract}

Background: Overall human health has been considered as physical, mental, and social health. The aim of the present study was to develop and measure Social Health Index in Iran by regions. Policymakers can implement evidence-based interventions by gaining knowledge about social health status.

Methods: To develop Social Health Index, social health indicators were collected by literature review and indicators whose information existed in provincial level. The final list of indicators was derived based on expert opinions. Then, data were normalized by comparative standardization. Using additive model, the total score of social health was calculated and provinces were ranked.

Results: Based on the composite index, including 39 indicators, a healthy society is properly characterized by lack of drug use, child labor, divorce, unemployed academics, child abuse, and smoking. The highest and lowest social health belonged to Yazd and Sistan and Baluchistan provinces, respectively.

Conclusion: This study showed the provinces' social health as an important tool for evidence-based policymaking. To monitor social health status, similar studies should be conducted every 3 to 5 years.

Keywords: Social health, Indicator, Measurement, Iran, Province

Conflicts of Interest: None declared

Funding: Social Health Office of Ministry of Health

*This work has been published under CC BY-NC-SA 1.0 license.

Copyright $\odot$ Iran University of Medical Sciences

Cite this article as: Zamankhani F, Abachizadeh K, Omidnia S, Abadi A, Hiedarnia MA. Composite social health index: Development and assessment in provinces of Iran. Med J Islam Repub Iran. 2019 (3 Aug);33:78. https://doi.org/10.47176/mjiri.33.78

\section{Introduction}

The World Health Organization (WHO) has identified social well-being as a key component of overall health: "Health is a state of complete physical,

mental, and social well-being and not merely the absence of disease or infirmity" (1). More than $50 \%$ of the causes contributing to physical and mental health disorders have social and environmental origins (2). Despite the greater progress in defining and measuring physical and mental health of individuals, there is little consensus on the definition of social health and its measurement due to the different definitions and methods of measurement

\footnotetext{
Corresponding author: Dr Kambiz Abachizadeh, k.abachizadeh@sbmu.ac.ir

1. Deputy of Health, Alborz University of Medical Sciences, Karaj, Iran

2. Social Determinants of Health Center, Shahid Beheshti University of Medical Sciences, Tehran, Iran

3. Department of Community Medicine, Faculty of Medicine, Shahid Beheshti University of Medical Sciences, Tehran, Iran.

4. Social Health Office, Health Deputy of Ministry of Health and Medical Education, Tehran, Iran

5. Social Determinants of Health Research Center, Shahid Beheshti University of Medical Sciences, Tehran, Iran
}

(3). Two approaches to measure social health are individual (micro) and societal (macro) viewpoints (3). Keyes assessed social health in individual level and described it as a quality of an individual's performance in the community and the quality of his/he $\mathrm{r}$ relationship with family and other social groups (4). Miringoff et al discussed social health at societal level. In this approach, Social Health Index examines the quality of life of nations and the problems of societies but pays little attention to individual problems (5). Developed countries have established social health indicators appropriate to their circumstances

$\uparrow$ What is "already known" in this topic:

Few studies have been conducted on measuring social health score in provinces of Iran.

\section{$\rightarrow$ What this article adds:}

The social health scores of provinces based on 39 indicators were calculated and the portrait of social health status of Iran was drawn. 
and each year they release social reports to inform policymakers and the public about the current state of the society. As a society attempts to address social issues more, it achieves vitality as a whole. Miringoff combined 16 objective indicators to portrait American social health in a single assessment. The selected indicators determined the circumstances of children, youths, adults, the elderly, and the general population. They annually calculated social health score at the national level across states since 1978 (6).

Following the second approach in 2010, Rafiye et al defined Iranian's social health index: a healthy society is one with high education and health insurance coverage, and low poverty, violence, growth rate, and unemployment. According to the social health index measurement, Tehran ranked first and Sistan and Baluchestan ranked last (7).

Hashemi et al considered monitoring social well-being in Iran through societal and individual indicators. In their study, 37 indicators were extracted but 23 indicators had available data at the national or international level. The remaining 14 of the variables required a new periodical measurement effort (3). The structure of the social health index will depend on the capacity to collect essential information; and it is not merely enough to conceptualize what should be ideal in such an index, as this practice is necessarily limited by access to data and the need to conduct a survey (8).

In Iran, few studies have been published on social health measurement at national and provincial level (9). In this paper, societal and individual indicators were combined to measure social health index at the provincial level in Iran based on available and valid data by regions. Knowledge, policy, planning, and decision making based on evidence will reduce mortality and burden of disease and promote health of people and the society.

\section{Methods}

This cross sectional study was conducted at the provincial level in Iran and in 2 phases: qualitative and quantitative. In the qualitative phase, the bottom-up approach was used to develop indicators. At first, the literature was reviewed from 1990 to 2016 to identify areas and to extract indicators for measuring social health. English databases, such as Social Sciences Citation Index, PubMed, Scopus, and Google Scholar, were searched. Persian databases, such as IranMedex, Magiran, IRANDOC, and SID, were also searched. The key words were as follow: social health, social health index, social health area, social health indicators, social health measurement, social health domain, social health category, social welfare, social wellbeing, and social capital. Also, a filter for social health insurance was added. Searches were performed on author names on useful articles and websites of Iran Sociology Association, National Institute of Health Research, Academy of Medical Sciences of Islamic Republic of Iran, and Institute for Innovation in Social Policy. An official document about social health indicator development by Hashemi et al at Ministry of Health was used (10). Finally, a pool of indicators was prepared.

\section{Selection of Indicators}

Data had to be available, official, and reliable; therefore, to ensure the accuracy of information, those indicators that were measured by official sources were used, including education, poverty, unemployment, drug use, and divorce. After a focused group discussion, researchers selected social health indicators derived from previous works in the Ministry of Health as the basis for questionnaire (10). A questionnaire based on 70 indicators was designed to determine which indicator had official and reliable data. In this study, a group of 3 researchers in 3 sessions determined which indicator had available data. Also, organizations as stakeholders were identified. Then, a questionnaire based on official document was sent to them to identify the existing data and their sources in those organizations.

Data collection: Official reports of Iran from 2007 to 2015 were used. Data were collected from the following official electronic and digital documents: 1389- IRMIDHS (11); National Statistic Center (12); STEPS 88; Absolute Indicator of Health in Islamic Republic of Iran Broadcasting (13); Year Book of Iran Drug Control Headquarters; National Organization for Civil Registration (14); Iranian Legal Medicine Organization; Ministry of Cooperative, Labor, and Social Welfare; Social capital (15); Department of Women's Affairs and Family; and Life Satisfaction score (16) . Eventually data of 54 indicators were collected.

-Prioritization and choice of weight: A questionnaire was designed to measure weight and accuracy for each indicator and coverage and collectivity of all indicators based on 54 indicators. Then, it was emailed to provincial experts who work in social health branch of medical universities. Eight experts filled the questionnaire and emailed it back. The mean and standard deviation of weight and accuracy for each indicator and coverage and collectivity of all indicators were calculated. The cutoff points of 8 for weight and 2 for accuracy were selected, and indicators below these cutoff points were omitted. Experts gave the score of 8 to the set of indicators as a whole for coverage and collectivity. Finally, 39 indicators were extracted.

Selected indicators were related to areas such as women, children, youths, health, education, violence, life satisfaction, social capital, and environment.

-Standardization: Since various indicators had various units, such as Rial, number, percent, and ratio, they had to be standardized. Indicators were standardized in 2 ways: comparative standardization and $\mathrm{z}$ - score. The comparative standardization method was used similar to HDI method by UNDP (17).

Standardization $=\frac{\text { Actual Value }- \text { Minimum Value }}{\text { Maximum Value }- \text { Minimum Value }} \times 100$

In this method, if the index is negative for other indicators, then, in the case of a fraction, the variable's value will be reduced from the highest value.

The value of each indicator ranged from 0 to 100 .

-Aggregation indicators and ranking: Individual indicators were synthesized into composite index using additive model (18). The score of indicators with weight and without weight adds to each other. The total score for each 
province was calculated.

-Validity of the study: The correlation between the 3 ways of calculation of social health was calculated 2 by 2 . The correlation was also calculated between the results of this study and those of Rafiye study.

-Social health situation was drawn on the map using Arc GIS 10.2.2. (19) and was classified in 6 categories on the map.

-The Ethics Committee of Shahid Beheshti University of Medical Sciences approved this research (ethics code: IR.SBMU.MSP.1395.128).

\section{Results}

The results of this study have been presented in several parts: selected prioritized indicators based on their importance; ranking of provinces with comparative standardization method considering indicators' weight and without weight; GIS map of social health; and correlation between studies.

\section{Selected prioritized indicators}

In this study, 54 indicators were reduced and prioritized to 39 based on experts' views. Addiction, child labor, divorce, educated unemployment, and child abuse were top 5 issues in this study (Table 1).
Ranking of provinces considering indicators' weight and without weight

Ranking of social health based on comparative standardization method with weight and comparative standardization method without weight is presented in Table 2. The top 3 provinces were Yazd, South Khorasan, and Ilam and the low ranked provinces were Sistan \& Baluchistan, Hormozgan, and Kohgiluyeh \& Boyer-Ahmad.

Score of Iran as a whole was approximately in the middle of the chart. Also, 16 provinces were above the national value and 15 were below it, with Tehran, the capital of Iran, at the seventh position. The following chart demonstrates the results (Fig. 1).

\section{GIS map of social health}

Inequalities of social health between areas have been explored. Green color demonstrates better performance and red color the worst performance (Fig. 2).

\section{Correlation between studies}

The correlation between this study and Rafiye study was calculated. Standardized comparison method without weight $(r=0.539)$ had a better correlation than standardized comparison method considering weigh $(\mathrm{r}=0.536)$.

\section{Discussion}

In this study, 39 indicators were extracted from 54 indi-

Table 1. Prioritization of 39 indicators based on importance

\begin{tabular}{|c|c|c|c|c|c|c|c|}
\hline No. & Indicator & $\begin{array}{l}\text { Mean of } \\
\text { importance }\end{array}$ & SD & No. & Indicator & $\begin{array}{l}\text { Mean of } \\
\text { importance }\end{array}$ & SD \\
\hline 1 & Prevalence of addiction to drugs & 9.9 & 0.4 & 21 & Urban household income & 8.5 & 1.2 \\
\hline 2 & $\%$ of child Labor (5-14 years old) & 9.5 & 0.9 & 22 & $\begin{array}{l}\text { Rate of literacy among people aged } 6 \text { and } \\
\text { older }\end{array}$ & 8.5 & 1.4 \\
\hline 3 & Marriage to divorce ratio & 9.4 & 0.8 & 23 & $\begin{array}{l}\text { Rate of unemployment among } 15 \text { year-olds } \\
\text { and older }\end{array}$ & 8.5 & 1.8 \\
\hline 4 & $\begin{array}{l}\% \text { of unemployed educated population to } \\
\text { total active educated population }\end{array}$ & 9.3 & 1 & 24 & Gender parity index (primary education) & 8.5 & 1.9 \\
\hline 5 & Rate of severe physical punishment (child) & 9.1 & 1.1 & 25 & $\begin{array}{l}\% \text { of cities over three hundred thousand } \\
\text { people that pollutants are measured }\end{array}$ & 8.4 & 1.5 \\
\hline 6 & $\%$ of inadequate care for children & 9 & 0.9 & 26 & $\%$ of female-headed households & 8.4 & 1.6 \\
\hline 7 & The prevalence of use of city hookah & 9 & 1.1 & 27 & $\begin{array}{l}\% \text { of birth before age } 18 \text { in women aged } 20- \\
24 \text { yrs. }\end{array}$ & 8.3 & 1.5 \\
\hline 8 & The prevalence of use of rural hookah & 9 & 1.2 & 28 & $\begin{array}{l}\text { Prevalence of women aged } 15-54 \text { yrs. with } \\
\text { one chronic disease }\end{array}$ & 8.3 & 0.9 \\
\hline 9 & $\begin{array}{l}\% \text { of life satisfaction among women } 15-24 \\
\text { yrs. }\end{array}$ & 8.9 & 1 & 29 & Rural household income & 8.3 & 1.2 \\
\hline 10 & Literacy rate among young women & 8.9 & 1.1 & 30 & Life satisfaction score (self-perception) & 8.3 & 1.5 \\
\hline 11 & Prevalence of smoking & 8.9 & 1.4 & 31 & $\%$ of children who reach the last primary & 8.3 & 1.6 \\
\hline 12 & $\begin{array}{l}\% \text { of access to potable water in rural re- } \\
\text { gions }\end{array}$ & 8.9 & 1.5 & 32 & Rate of net completion of primary school & 8.3 & 1.7 \\
\hline 13 & $\%$ of conflict referred to the coroner & 8.9 & 0.6 & 33 & Social capital & 8.1 & 1 \\
\hline 14 & Rate of net timely entry to primary school & 8.9 & 0.8 & 34 & Rate of transition to middle school & 8.1 & 1.2 \\
\hline 15 & $\begin{array}{l}\% \text { of women } 15-54 \text { yrs. Who have used } \\
\text { smoke products last month }\end{array}$ & 8.6 & 0.5 & 35 & $\%$ of slim children (weight for height) & 8.1 & 1.4 \\
\hline 16 & $\begin{array}{l}\% \text { of access to potable water in urban re- } \\
\text { gions }\end{array}$ & 8.6 & 1.2 & 36 & $\begin{array}{l}\text { Rate of employment among those aged } 15 \\
\text { and older }\end{array}$ & 8.1 & 1.8 \\
\hline 17 & $\begin{array}{l}\text { Rate of unemployment among 15-29 year- } \\
\text { olds }\end{array}$ & 8.6 & 1.8 & 37 & Obesity rate & 8 & 0.9 \\
\hline 18 & Rate of verbal punishment (children) & 8.5 & 0.8 & 38 & NGOs active in women's affairs & 8 & 1.8 \\
\hline 19 & $\begin{array}{l}\% \text { of the population covered by basic insur- } \\
\text { ance }\end{array}$ & 8.5 & 0.9 & 39 & $\begin{array}{l}\% \text { of women aged } 15-24 \text { yrs. who are very } \\
\text { or fairly happy }\end{array}$ & 8 & 2 \\
\hline 20 & $\begin{array}{l}\% \text { of children } 0-17 \text { yrs. who have lost one } \\
\text { of their parents }\end{array}$ & 8.5 & 1.2 & & & & \\
\hline
\end{tabular}




\begin{tabular}{|c|c|c|c|c|}
\hline Province & Score with weight & Rank & Score without weight & Rank \\
\hline Yazd & 23618.6 & 1 & 2730.93 & 1 \\
\hline South khorasan & 22960.7 & 2 & 2653.74 & 2 \\
\hline Ilam & 22258.5 & 3 & 2575.4 & 3 \\
\hline Zanjan & 22150.23 & 4 & 2557.91 & 4 \\
\hline Semnan & 21884.54 & 5 & 2534.2 & 5 \\
\hline Qazvin & 21812 & 6 & 2532.3 & 6 \\
\hline Tehran & 21470.1 & 8 & 2497.6 & 7 \\
\hline Markazi & 21524.23 & 7 & 2489.3 & 8 \\
\hline East Azerbaijan & 21380.71 & 9 & 2479.02 & 9 \\
\hline Charmahal \& Bakhtiari & 20808.53 & 10 & 2415.91 & 10 \\
\hline Isfahan & 20673.9 & 11 & 2398.23 & 11 \\
\hline Khuzestan & 20650.43 & 12 & 2393.8 & 12 \\
\hline Ardabil & 20209.82 & 13 & 2340.4 & 13 \\
\hline Hamadan & 19925.12 & 14 & 2304.73 & 14 \\
\hline Alborz & 19664.2 & 15 & 2278.5 & 15 \\
\hline Kurdistan & 19597.3 & 16 & 2265.61 & 16 \\
\hline Iran & 19343.4 & 17 & 2241 & 17 \\
\hline Mazandaran & 19101.4 & 19 & 2223.3 & 18 \\
\hline Qom & 19194.2 & 18 & 2219.2 & 19 \\
\hline Fars & 19073.1 & 20 & 2215.01 & 20 \\
\hline Gilan & 18963.3 & 21 & 2200.7 & 21 \\
\hline North Khorasan & 18741.6 & 22 & 2167.02 & 22 \\
\hline Khorasan Razavi & 18612.91 & 23 & 2154.64 & 23 \\
\hline West Azerbaijan & 18384.2 & 24 & 2127.74 & 24 \\
\hline Bushehr & 18258.43 & 25 & 2114.4 & 25 \\
\hline lorestan & 18102.43 & 26 & 2107.93 & 26 \\
\hline Kerman & 17979.7 & 27 & 2091.14 & 27 \\
\hline Golestan & 17794.1 & 28 & 2063 & 28 \\
\hline Kermanshah & 17562.73 & 29 & 2037.9 & 29 \\
\hline Hormozgan & 16917.4 & 30 & 1953.2 & 30 \\
\hline Kohgiluyeh \& Boyer-Ahmad & 16738.3 & 31 & 1939.3 & 31 \\
\hline Sistan \& Baluchistan & 13817.01 & 32 & 1582.64 & 32 \\
\hline
\end{tabular}

cators whose information was collected. Priorities were substance abuse, child labor, marriage to divorce ratio, educated unemployed population to total active educated population, rate of severe physical punishment (child), inadequate care for children, the prevalence of use of city hookah, the prevalence of use of rural hookah, life satisfaction score among women aged 15-24 yrs., and literacy rate in young women. The index also addressed social issues, socioeconomic situation, and environmental issues. Qualitative studies had been conducted on the most im-



Fig. 1. Bar chart of Iran Social Health Index by regions 


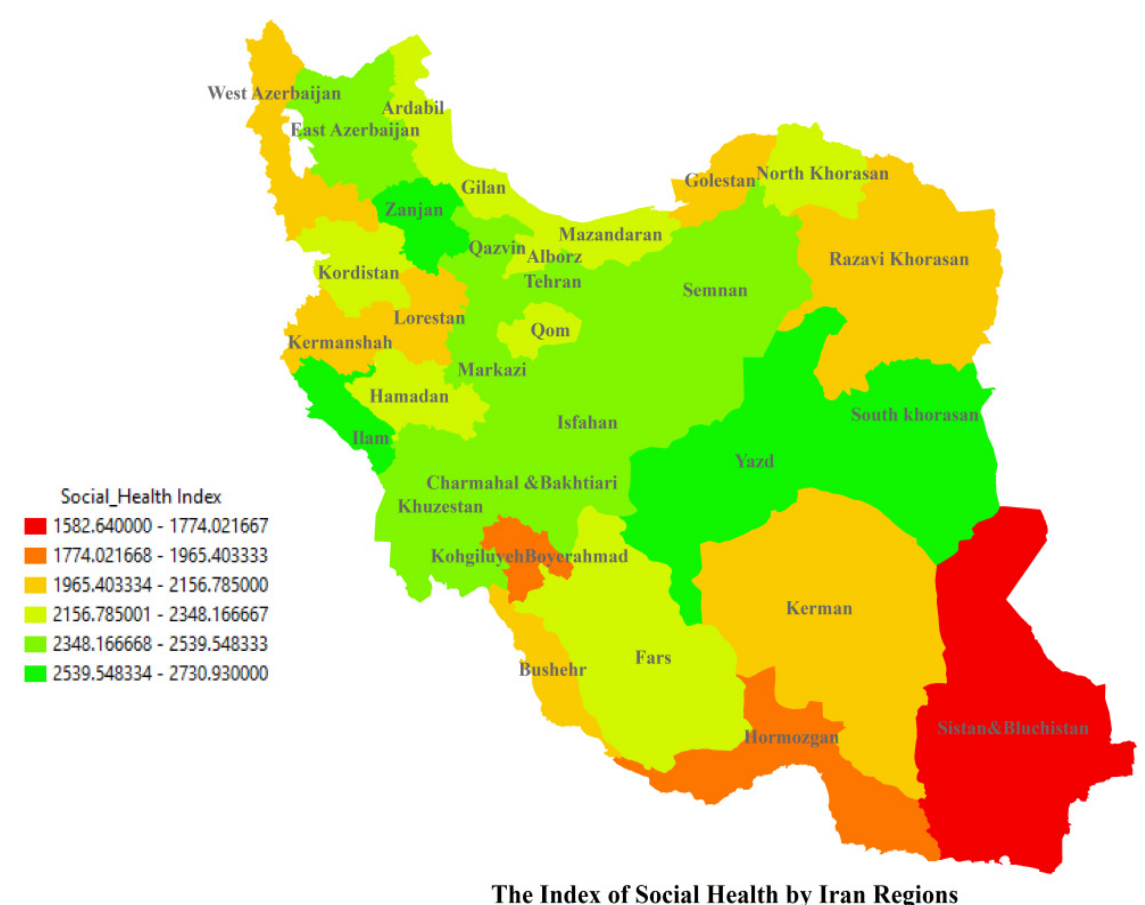

Fig. 2. Social health of Iran by regions

portant social concerns in the country. In 2007, Vameghi et al found that addiction, unemployment, violence, social distrust, and economic poverty are social concerns (20). In 2007, Motamedi et al asked 1000 experts to prioritize social concerns in Iran and they found that unemployment, addiction, and poverty were 3 main social concerns (21). In the present study, addiction, child abuse and neglect, tobacco, and educated unemployment were the most important social concerns.

According to 39 standardized indicators with equal weight, top 5 provinces were Yazd, South Khorasan, Ilam, Zajan, and Semnan and 5 low ranked provinces were Golestan, Kermanshah Hormozgan, Kohgiluyeh \& BoyerAhmad, and Sistan \& Bluchistan. Also, 16 provinces were above the national score and15 were below the national score. Although Tehran had the highest family income, it stayed at seventh position. In this study, the major geographical differences in performance of social health were distinguished in the country. GIS map of social health showed that the best social health performance is seen from northwest to central and east of Iran and the worst in the southeast and south of the country.

In each country, social health monitoring needs native indicators. In Iran, the only study that had measured social health index was that of Rafiye. They extracted 17 indicators by Delphi method. In the quantitative part, only 6 indicators were used to calculate social health. The indicators included population growth, poverty, insurance coverage, literacy, murder, and unemployment. According to their findings, Tehran, Semnan, and Isfahan were the top 3 provinces, respectively, and the 3 provinces with the lowest social health were Sistan \& Baluchistan, Lorestan, and Ilam. In the present study, Ilam gained a high rank; however, Sistan \& Bluchistan stayed at the bottom of the table. In HDI study in 2009 by Sabermahani et al, Ilam obtained a good rank in contrast to 2001 (22). However, Sistan \& Bluchistan stayed at the bottom of the table.

In this study, comparative standardization method without weight was used. Similar studies have used equal weight such as HDI and SHI (23).

Strengths of the study were using more indicators than previous studies, using environmental indicators from few quantitative evidences of social health in Iran, and paying attention to subgroups such as children, women, and highrisk behaviors. Some organizations had a weak cooperation with researchers, and it would have been helpful if more experts took part in prioritization.

It is suggested to estimate the score of Social Health Index based on census 2016-IRMIDHS and other updated data to monitor social health trends in the country. Also, policymakers should pay attention to evidences to make decisions.

\section{Conclusion}

This article provides a comparison of social health status among 32 provinces of Iran. In this study, it was found that 6 of the bottom 10 provinces are in the south, so the policymakers should specially attend to improve the social health status in this region. Measuring social health index every 3 to 5 years is useful to monitor social health status of Iran. Also, measuring Social Health Index is a strategic approach to identify and track equity in the country.

\section{Acknowledgements}

We would like to thank the head and staff of the Social Health Office of Ministry of Health for supporting the research. Also, we thank the organization representatives and provincial experts for their cooperation. 


\section{Conflict of Interests}

The authors declare that they have no competing interests.

\section{References}

1. Jadad AR, O'Grady L. How should health be defined? Br Med J (Online). 2008;337.

2. Organization. WH. Promoting mental health: Concepts, emerging evidence, practice: Summary report.Geneva: WHO 2004

3. Hashemi FM, Pourmalek F, Tehrani A, Abachizadeh K, Memaryan N, Hazar N, et al. Monitoring Social Well-Being in Iran. Soc Indicat Res. 2016;129:1-12.

4. Abachizadeh K, Omidnia S, Memaryan N, Nasehi A, Rasouli M, Tayefi B, et al. Determining dimensions of Iranians' individual social health: A qualitative approach. Iran J Pub Health. 2013;42(1):88-92.

5. Miringoff ML, Opdycke S. America's social health: putting social issues back on the public agenda. Newyork: Routledge; 2014.

6. Miringoff ML. Index of social health: monitoring the social well-being of the nation. Tarrytown: Fordham Institute for Innovation in Social POlicy 2003.

7. Rafiey H, Amini R, Samiei M, Akbarian M. The Social Health of Iran: From a Consensus-based Definition to an Evidence-based Index. Iran J Psiciatry Clin Psychol. 2010;3(62):299-300.

8. Lalonde C. Creating an index of healthy Aboriginal communities. Developing a Healthy Communities Index: a collection of papers. Canadian Institute of Health Information, Ottawa. 2005.

9. Abachizadeh K, Omidnia S, Hajebi A, Shekarriz-Foumani R, Mohseni M, Zamankhani F. Measuring Self-perceived Social Health of Iranians; Finding from Iran Social Health Survey. Novel Biomed. 2017;5(3):91-7.

10. Ministry of Health. Social Indicators of Iran. Tehran: 2012.

11. Rashidian A, Karimi-Shahanjarini A, Khosravi A, Elahi E, Beheshtian M, Shakibazadeh E, et al. Iran'Multiple Indicator Demographic and Health Survey (IrMIDHS-2010): Study protocol. Int J Prev Med. 2014;5(5).

12. IranCencusBureau. Statistical Year Book 2011. Tehran [updated 2015 oct]; Available from: https://nnt.sci.org.ir/sites/Apps/yearbook/ Lists/year book req/Item/newifs.aspx?List=97c00882-734c-4417831a-633d795b18ce\&Root.

13. Khosravi A, Najafi F, Rahbar M, Motlagh M, Kabir M. Absolute indicator of health in the Islamic Republic of Iran Broadcasting. Department of Health Ministry of Health and Medical Education Development Center network and health. 2009;1(2000):1-439.

14. http://www.sabteahval.ir/Upload/Modules/Contents/asset99/t-94.pdf.

15. Abdellahi M, Mousavi MT. Social capital in Iran: Current status, prospect, and feasibility Social Welfare. 2007;6(25):195-234

16. Abachizadeh K, Nasehi A, Omidnia S, Nikfarjam A, Masoodifarid $\mathrm{H}$, Khosravi A, et al. Measuring Positive Health of Iranians; Finding from Iran Social Health Survey (ISHS). Tehran: Shahid Beheshti Medical University of Science. 2014.

17. Jany-Catrice $F$. The french regions and their social health. Soc Indicat Res. 2009;93(2):377-91.

18. Maggino F, Zumbo BD. Measuring the Quality of Life and the Construction of Social Indicators In: Land KC, editor. Handbook of Social Indicators and Quality of Life Research: Springer Science+Business Media; 2012. p. 201-38.

19. Arc GIS for Desktop. version 10.2.2.3552 ed: Esri; 2014.

20. Vameghi M, Madani S, Rafiey H. Social problems of Iran from the point of view of managers and experts of social problems. Tehran: University of Social Welfare and Rehabilitation. 2007.

21. Motamedi SH. To make priority of social problem in Iran. Soc Welfare Quart. 2007;6(24):327-47.

22. Sabermahani A, Barouni M, Seyedin H, Aryankhesal A. Provincial human development index, a guide for efficiency level analysis: the case of Iran. Iran J Pub Health. 2013;42(2):149.

23. Hagerty M, Land $\mathrm{K}$. Issues in composit index construction: The mesurement of overall quality of life. In: Land K, Michalos AC, Sirgy $\mathrm{J}$, editors. Handbook of social indicators and quality of life research: Springer; 2012. p. 181-200. 